\title{
Factors Influencing Selection of Oral Hygiene Aids Among an Urban Population of Kathmandu District
}

\author{
Dr. Sunita Khanal, ${ }^{1}$ Dr. Rosina Bhattarai, ${ }^{1}$ Dr. Sujita Shrestha, ${ }^{1}$ Dr. G. Nagaraja Rao $^{1}$ \\ ${ }^{1}$ Department of Community Dentistry, Kantipur Dental College, \\ Kathmandu, Nepal.
}

\begin{abstract}
Introduction: The exact origin of mechanical device for cleaning teeth is not known. In past, plants with high aromatic properties were chewed by people in twigs form. These twigs freshened breath and spread out fibres at their tips as they were used for cleaning teeth and gum surfaces. China was the first country to invent toothbrush. Widely used oral hygiene aids are toothbrush and toothpaste.

Objective: To assess the factors influencing selection of oral hygiene aids among an urban population of Kathmandu district.

Methods: A cross-sectional analytical study was conducted during July-October 2019 among the adult population from outreach programs and outpatient department of Kantipur Dental College Teaching Hospital after receiving ethical approval from Institutional Review Committee. Convenience sampling was done. A predesigned questionnaire was used for data collection purpose. Data was entered in Microsoft Excel and analysed using SPSS v.20 software. Chi-square test was done at $\leq 0.05$ level of significance.

Results: Among 301 participants, 133 (44.2\%) were male and 168 (55.8\%) were female. The factors that influenced selection of toothpaste were: taste 169 (56.1\%), fluoride content 160 (53.2\%), previous experience 209 (69.4\%), dentist's advice 180 (59.8\%). Factors that influenced selection of toothbrush were: texture of bristle 274 (91\%), cost of toothbrush 169 (56\%), brand 211 (70\%), previous experience, 200 (66.4\%), 184 (61\%) by size of head of toothbrush, and 184 (61.1\%) by dentist's advice.

Conclusion: Previous experience, cost, and dentist's advice seemed influential factors in the choice of oral hygiene aids among the urban population of Kathmandu district.

Keywords: Influencing; oral hygiene aids; selection.
\end{abstract}

\section{INTRODUCTION}

The two most common dental problems are dental caries and periodontal disease and bacterial plaque is the main aetiological factor in both the cases. Studies have shown that the removal of bacterial plaque is possible only through good oral hygiene practices. ${ }^{1,2}$ Oral hygiene is the practice of keeping one's mouth clean and free from diseases and other problems. ${ }^{3}$ Globally 4.2 billion people own a toothbrush with an average cost of US \$1 per brush. ${ }^{4}$

\footnotetext{
Correspondence:

Dr. Sunita Khanal

Department of Community Dentistry, Kantipur Dental College, Kathmandu, Nepal.

email: khanal.sunita729@gmail.com

Citation

Khanal S, Bhattarai R, Shrestha S, Rao GN. Factors Influencing Selection of Oral Hygiene Aids Among an Urban Population of Kathmandu District. J Nepal Soc Perio Oral Implantol. $2020 \mathrm{Jul}$ Dec;4(8):57-60.
}

Various studies have shown that factors influencing the choice of oral hygiene aids are: product class knowledge, quality, packaging, promotion, familiarity with a channel, brand awareness, family influence, professional influence, etc. $^{5}$ Very little information is available regarding the factors influencing the selection of oral hygiene aids among Nepalese population.

The main objective of the study was to assess factors influencing selection of oral hygiene aids among an urban population of Kathmandu district.

\section{METHODS}

Analytical cross-sectional study was conducted among the patients visiting Outpatient Department and outreach programs of Kantipur Dental College Teaching Hospital and Research Centre during July-October 2019. Ethical clearance was obtained from Institutional Review Committee of Kantipur Dental College Teaching Hospital and research centre before starting the study. Informed written consent was obtained from the patients before enrolling them in the study. Participants who were $\geq 18$ years old and who gave 
consent to participate in the study were included. Sample size was calculated by taking $\mathrm{p}=0.26 .6$

It was calculated to be 296. Convenience sampling technique was used for data collection. A structured predesigned questionnaire was used for data collection purpose.6 A single interviewer was used for data collection purpose. Factors that were considered for the choice of toothpaste were the cost, colour, flavour/taste, packaging, content (herbal/fluoride), media advertisement, family influence, and advice of dentist whereas factors considered for the choice of toothbrush were texture of the bristle, cost, packaging, brand, media advertisement, size of the head of toothbrush, family influence, and advice of dentist. For each factors, two options influenced and not influenced were there. Before starting the study, the questionnaire was pretested among $10 \%$ of the sample size (30 patients), who were not included in the final analysis to ensure reliability of the questionnaire. The Cronbach alpha value was found to be $>0.7$.

Data was entered and coded in Microsoft Excel Sheet and analysed using IBM SPSS Statistics for Windows, version 20 (IBM Corp., Armonk, N.Y., USA). P value of $\leq 0.05$ was considered to be statistically significant. Chi-square test was used to assess the association of variables.

\section{RESULTS}

Altogether 301 participants participated in study, among them 168 (55.8\%) were female (Figure 1), out of which $263(87.4 \%)$ were literate and 38 (12.6\%) were illiterate

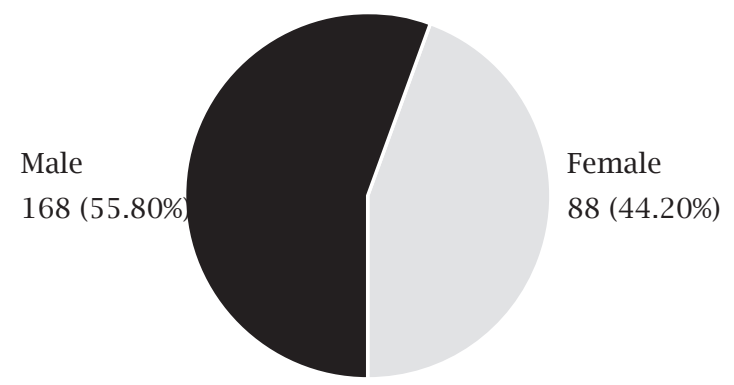

Figure 1: Genderwise distribution of participants.
(Figure 2), maximum number of participants were unemployed 86 (28.6\%) (Figure 3).

When asked about their oral hygiene habits, it was found that 298 (99\%) used toothbrush and toothpaste to clean their teeth. Among them 293 (97.3\%) used manual toothbrush, 7 (2.3\%) used powered toothbrush and 1 (0.4\%) did not use toothbrush.

Factors that influenced selection of toothpaste the most were: taste 169 (56.1\%), fluoride content 160 (53\%) but 78 (26\%) did not know what fluoride is, previous experience 209 (69.4\%) and, advice by dentist 180(59.8\%), (Table 1).

Factors that mostly influenced selection of toothbrush were: texture of bristle 274 (91\%), cost 169(56\%), brand 211(70\%), previous experience 200 (66.4\%), size of head of toothbrush 184(61\%), and dentist's advice 184 (61.1\%), (Table 1).

Chi-square test was applied to assess the association of gender and selection of oral hygiene aids. It was found that only taste of toothpaste was statistically significant (Table 2).

Chi square test was applied to assess the association of academic qualification and selection of oral hygiene aids. Fluoride content in toothpaste and dentist's advice seemed statistically significant with toothpaste selection. In toothbrush selection, texture of bristle, brand, size of head of toothbrush, and dentist's advice seemed statistically significant while other factors had no significant association (Table 3).

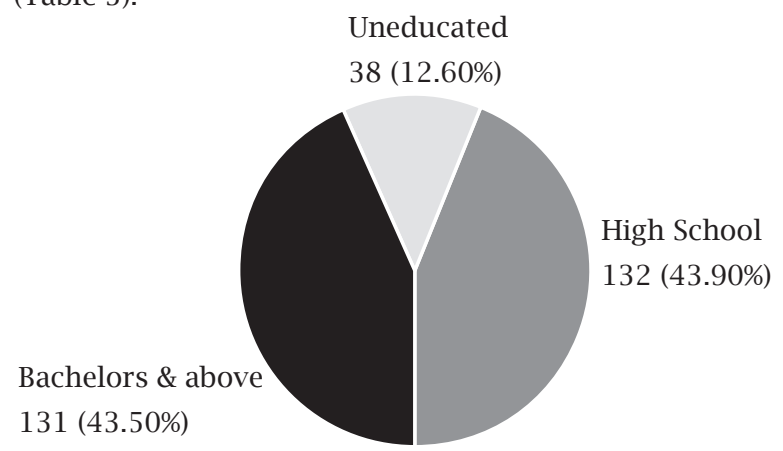

Figure 2: Academic qualification of participants, $\mathbf{n}(\%)$.

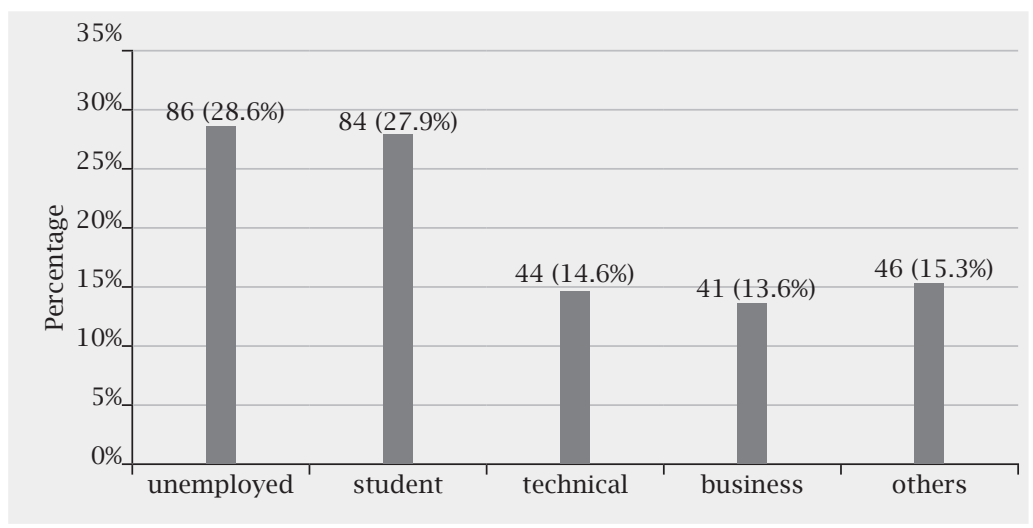

Figure 3: Occupation of participants, $\mathbf{n}(\%)$. 
Table 1: Response of participants towards selection of toothpaste and toothbrush, $\mathbf{n}$ Factors Influence (n\%)

Generalised chronic periodontitis (n\%)

Factors influencing selection of toothpaste

\begin{tabular}{|l|c|c|}
\hline Colour & $102(33.90)$ & $199(66.10)$ \\
\hline Cost & $119(39.50)$ & $182(60.50)$ \\
\hline Taste & $169(56)$ & $132(44)$ \\
\hline Packaging & $70(23.30)$ & $231(76.70)$ \\
\hline Media & $98(32.6)$ & $162(53.8)$ \\
\hline Family influence & $139(46.2)$ & $176(58.5)$ \\
\hline Herbal content & $125(41.5)$ & $93(31)$ \\
\hline Previous experience & $208(69)$ & $120(40)$ \\
\hline Dentist's advice & $181(60)$ & $63(21)$ \\
\hline Fluoride content & $53(160)$ & $27(9)$ \\
\hline Factors influencing selection of toothpaste & & $132(44)$ \\
\hline Texture of bristle & $274(91)$ & $90(29.9)$ \\
\hline Cost & $169(56)$ & $208(69.1)$ \\
\hline Brand & $211(70.1)$ & $212(70.4)$ \\
\hline Packaging & $93(30.9)$ & $166(55.1)$ \\
\hline Media & $89(29.6)$ & $101(33.6)$ \\
\hline Family influence & $135(44.9)$ & $119(39.5)$ \\
\hline Previous experience & $200(66.4)$ & $117(38.9)$ \\
\hline Size of head of toothbrush & $182(60.5)$ & $184(61.1)$ \\
\hline Dentist's advice & & \\
\hline
\end{tabular}

Table 2: Gender wise comparison on influence of taste of toothpaste, $\mathbf{n}(\%)$.

\begin{tabular}{|c|c|c|c|}
\hline Gender & Influence n(\%) & No influence $\mathbf{n}(\%)$ & $P$ value \\
\hline Male & 84 (63.2\%) & $49(36.8 \%)$ & \multirow{3}{*}{0.029} \\
\hline Female & 85 (50.5\%) & $83(49.5)$ & \\
\hline Total & 169 & 132 & \\
\hline Chi-square test & & & \\
\hline
\end{tabular}

Table 3: Comparison of academic qualification and selection of toothpaste and toothbrush, $\mathbf{n}(\%)$.

\begin{tabular}{|c|c|c|c|c|c|}
\hline & & Uneducated & High school & Bachelors and above & P value \\
\hline \multicolumn{6}{|c|}{ Factors influencing selection of toothpaste } \\
\hline & & $\mathrm{n}(\%)$ & $\mathrm{n}(\%)$ & n (\%) & \\
\hline \multirow{3}{*}{ Fluoride content } & Influence & $10(26.3)$ & $69(52.3)$ & $81(61.8)$ & \multirow{3}{*}{0.002} \\
\hline & No influence & $12(31.6)$ & $24(18.1)$ & $26(19.84)$ & \\
\hline & Don't know Fluoride & $16(42.1)$ & 39 (29.55) & $24(18.3)$ & \\
\hline \multirow{2}{*}{ Dentist's advice } & Influence & $22(57.89)$ & $67(50.76)$ & $91(69.5)$ & \multirow{2}{*}{0.008} \\
\hline & No influence & $16(42.11)$ & $65(49.2)$ & $40(30.5)$ & \\
\hline \multicolumn{6}{|c|}{ Factors influencing selection of toothbrush } \\
\hline \multirow{2}{*}{ Texture of Bristle } & Influence & $29(76.3)$ & $119(90.1)$ & $126(96.2)$ & \multirow{2}{*}{0.001} \\
\hline & No influence & $9(23.7)$ & $13(9.9)$ & $5(3.8)$ & \\
\hline \multirow{2}{*}{ Brand } & Influence & $21(55.3)$ & $87(65.9)$ & $103(78.6)$ & \multirow{2}{*}{0.008} \\
\hline & No influence & $17(44.74)$ & $45(34.1)$ & $28(21.4)$ & \\
\hline \multirow{2}{*}{$\begin{array}{l}\text { Size of head of } \\
\text { toothbrush }\end{array}$} & Influence & $17(44.74)$ & 83 (62.9) & $83(63.4)$ & \multirow{2}{*}{0.016} \\
\hline & No influence & $21(55.3)$ & $49(37.1)$ & $48(36.6)$ & \\
\hline \multirow{2}{*}{ Dentist's advice } & Influence & $23(60.5)$ & $71(53.8)$ & $91(69.5)$ & \multirow{2}{*}{0.008} \\
\hline & No influence & $15(39.5)$ & $61(46.2)$ & $40(30.5)$ & \\
\hline
\end{tabular}




\section{DISCUSSION}

This study was conducted among the 301 (133, (44.2\%) male, 168 (55.8\%) female) individuals of Kathmandu district. Majority of the participants: $99 \%$ used toothbrush and toothpaste to clean their teeth which is similar to other studies. ${ }^{6-9}$ The extensive use of toothbrush among the participants may be an indication of their shift towards usage of modern tools.

The results of current study showed that the factors influencing choice of toothpaste were taste, fluoride content, previous experience, and advice by dentist. This is in accordance with other studies. ${ }^{6,10}$ Most of the customers use certain brand of toothpaste only for the taste. Peppermint taste was found to be the most preferred one in the present study with a belief that it provides the user with a sense of freshness and prevents bad breath.

Previous experience also influenced choice of both the toothpaste and toothbrush in our study suggesting that if respondents are satisfied with a particular product, they will use regularly.

Participants preferred fluoridated toothpaste to protect their teeth from decay process. However, few did not know about importance of fluoride which shows lack of awareness about the composition of toothpaste and needs to be immediately addressed.

The factors that affected selection of toothbrush were: texture of bristle, cost of toothbrush, brand, and previous experience, size of head of toothbrush, and dentist's advice which is in accordance with other studies ${ }^{4,6}$ but in contrast to the study conducted by Sharda and Sharda. ${ }^{11}$

The texture of bristle was most influential factor while choosing the toothbrush in the present study. Soft bristle was the most preferred one which is similar to other studies ${ }^{6,9}$ Cost was also an influential factor for people as they preferred toothbrush ranging from NRs. 50-100. Brands most commonly used are
Colgate, Sensodyne, and Oral B. Advice by a dentist was also an influential factor in present study which could be because the study area is hospital and outreach programs conducted by hospital itself.

Factors like beauty, media advertisement, and herbal contents added had no influence in the selection of oral hygiene aids which is similar to the study conducted by Opeodu and Gbadebo6 but in contrast to other studies.,11-13

There was significant difference in the selection of toothpaste based on taste in male and female. Academic qualification was found to be statistically significant with fluoride content and dentist's advice in choosing toothpaste. Also, texture of bristle, size of head of toothbrush, brand, and dentist's advice were statistically significant with choosing toothbrush. This may be due to the fact that as qualification level changes knowledge level also changes.

Since convenience sampling technique was used, findings cannot be generalised. This study serves as a pilot study for future studies.

\section{CONCLUSION}

Consumer behaviour is very difficult to predict. In this study, selection of toothbrush and toothpaste were mainly influenced by previous experience and dentist's advice. So, dental professionals should spend more time in educating and motivating the patients about the oral hygiene practices and the products so that incidence of dental diseases could be reduced. Manufacturers should also give preference to people's health as well as choice before manufacturing oral hygiene aids so that people will use their products forever.

\section{ACKNOWLEDGEMENT}

We would like to thank all the patients who gave their valuable time and participated in this study.

\section{Conflict of Interest: None.}

\section{REFERENCES}

1. Ainamo J, Parviainen K. Occurrence of plaque, gingivitis and caries as related to self-reported frequency of toothbrushing in fluoride areas in Finland. Community Dent Oral Epidemiol. 1979;7(3):142-6.

2. Petersen PE. Challenges to improvement of oral health in the 21st century-the approach of the WHO Global Oral Health Programme. Int Dent J. 2004;54(S6):329-43.

3. Topping G, Assaf A. Strong evidence that daily use of fluoride toothpaste prevents caries. Evid Based Dent. 2005;6(2):32.

4. Balasubramaniam A, Parangimalar Diwakar MK, Brinda B. Factors influencing selection of manual toothbrush among an urban population in Chennai City, India: A cross-sectional study. J Indian Assoc Public Health Dent. 2017;15:388-91.

5. Vani G, Babu MG, Panchanatham N. Toothpaste Brands-A Study of consumer behavior in Bangalore city. J Econ Behav Stud. 2010;1(1):273-9.

6. Opeodu OI, Gbadebo SO. Factors Influencing Choice of Oral Hygiene Products by Dental Patients in a Nigerian Teaching Hospital. Ann Ibadan Postgrad Med. 2017;15(1):51-6.

7. Logaranjani A, Mahendra J, Perumalsamy R, Narayan RR, Rajendran S, Namasivayam A. Influence of media in the choice of oral hygiene products used among the population of Maduravoyal, Chennai, India. J Clin Diagnostic Res. 2015;9(10):ZC06-8.

8. Umanah AU, Braimoh OB. Oral hygiene practices and factors influencing the choice of oral hygiene materials among undergraduate students at the University of Port Harcourt, Rivers State, Nigeria. J Dent Allied Sci 2017;6:3-7.

9. Kote S, Dadu M, Sowmya AR, Aruna DS, Arora D. Knowledge, attitude and behaviour for choosing oral hygiene aids among students of management institutes, Ghaziabad, India. West Indian Med J. 2013;62(8):758-63.

10. Uma S, Arun T, Ashika Y. A survey on the various factors that influence a customer's choice of toothpaste in Mogappair Population. Int J Curr Res. 2019;11(3):1959-64

11. Sharda A, Sharda J. Factors influencing choice of oral hygiene products used among the population of Udaipur, India. Int J Dent Clin. 2010;2(2):7-12.

12. Singh S. Effectiveness of advertisement on toothpaste product : a case study in Jhajjar district. Int J Appl Res. 2017;3(1):403-5.

13. Niha N, Gayatri Devi R, Jyothipriya A. Choice of toothpaste among undergraduate dental students. Drug Invent Today. 2019;12(5):862-5. 